\title{
Preface
}

Society holds together and functions in large part through the moral systems of everyday life and of codified law. The historical evolution of social structure is intimately bound up with the evolution of moral systems. The study of moral judgment is thus important not only at the psychological level but also at the societal level.

Concepts of recompense are prominent in law and everyday life, but experimental analysis has been minimal. This seems surprising in view of the extensive consideration given to concepts of responsibility and punishment. Recompense is an important contributor to social cohesiveness, and its psychological analysis would contribute to more effective social evolution.

Moral cognition is here considered part of general social cognition. This view is warranted by the discovery of a general cognitive algebra that applies equally across moral and nonmoral domains.

The present experiments extend this view by showing that the basic blame schema, namely, intent-damage averaging, applies also to the the third variable of recompense. Paradoxically, the effect of recompense is substantially larger than the effect of the harm for which recompense is made. This paradoxical result is more pronounced at younger ages, moreover, which suggests that it may have a biological base in submission-acceptance reactions.

The averaging rule for recompense is age-invariant down to 4 years of age. Values develop and change, but the integration schema is constant. Hcre, as in some other areas, cognitive algebra provides an underlying invariance, a platform for further analysis. Cognitive algebra can help unravel the structure of recompense as well as measure personal values with some genuine comparability across age and culture.

One line of further work lies in cooperative inquiry of psychology and law together. Experimental analysis is essential for cognitive theory of judgmentdecision in legal settings. The theory of information integration can help in this endeavor through the method of personal design, that is, by constructing experiments tailored to the value and experiential systems of each individual. This approach can contribute to development of a more human law and a more humane society. 
Chapter 3

\section{MORAL ALGEBRA \\ OF HARM AND RECOMPENSE}

\section{Wilfried Hommers}

Norman H. Anderson

The moral rule not to do harm has a corollary moral rule to undo harm that is done. This moral rule of undoing harm is well recognized in everyday life. A child who dirties some object may be required to clean it. A person who insults another may be required to apologize. In married couples, recompense in the form of gifts or soft words is often part of "making up" for distressful acts. So ubiquitous is the moral rule of recompense that at least one philosopher (Ross, 1930, p. 21) has elevated it to a prima facie duty.

In law, too, recompense has a basic role. In civil law, the court may impose some form of reparation for breach of contract or for certain classes of property damage or personal injury. In criminal law, the judge may impose reparation as part of the sentence. A more general outlook on reparation appears in the social doctrine that criminals "must pay their debt to society."

Despite its moral importance, recompense has received little attention from psychologists. The treatment of compensation for harmdoing by Walster, Walster, and Berscheid (1978) cites a variety of sociolegal observations but few experimental studies. Current theories of moral judgment generally ignore issues associated with positive aspects of undoing harm.

One difficulty in studying recompense is that it usually involves other moral variables. Recompense ordinarily involves reference to the harm for which recompense is made, and evaluation of harm may require taking culpability into account. Various kinds of mitigating circumstances may also be relevant. Hence the study of recompense cannot get very far without capability for handling multiple determination.

This chapter takes up the study of recompense as part of a general theory of moral judgment that can handle problems of multiple determination. The basic theme is that moral judgment follows well defined cognitive rules. These rules govern the valuation of the operative moral variables in the context of the prevailing stimulus field and their integration into moral responses. 
Of special interest is that some moral rules appear to have simple algebraic forms. For example, several studies have supported an averaging rule, Punishment $=$ Intent + Damage, for the classical intent-damage question (Grueneich, 1982; Hommers \& Anderson, 1985; Leon, 1976, 1980, 1982, 1984; Surber, 1977, 1982; see also Anderson, Volume III, Chapter 5). The moral algebra of recompense, however, has not been investigated. One question in the present studies is whether the Intent + Damage rule still holds when the variable of recompense is added. A second question concerns the nature of the rules governing the integration of recompense with intent and with damage.

\section{EXPERIMENTAL STUDIES}

Subjects were told stories about two stamp collectors, one of whom ruined some stamps belonging to the other. They were told to imagine that they were the victim and to say how much the offender should be punished. This ruined stamp scenario was chosen because it seemed to possess similar quality across an extended age range. General features of method were similar across the four experiments and will be summarized in this initial section on method.

Design. The main design was a $3 \times 2 \times 3$ factorial, with three levels of culpa, two levels of damage, and three levels of recompense. The three levels of culpa described accidental, careless, and intentional acts as follows (using personal pronouns from the male version of the instructions). The accidental condition was "He was very careful and used the pair of tweezers. He concentrated very much on handing you a stamp with the tweezers. But, he did not see his glass of kool-aid and spilt it." The careless condition was "The open inkpot stood on his side of the table. You told him about the danger. But, he left the inkpot there. Later on, he pushed against it and spilt it." The intentional level was "He wanted your best stamp. But, you did not wish to exchange your best stamp. He became furious and poured ink on your stamp." The term, culpa, suggested by Hommers (1983a), seems preferable to the usual terms, intent and motive, to denote the operative variable of social responsibility.

The two levels of damage stated the number of stamps that were ruined, 2 or 10, and 2 or 16 , in the various experiments. The three levels of recompense stated that none, half, or all of the ruined stamps were replaced by the offender. In addition to this complete three-factor design, certain two-factor and one-factor designs were also included in various experiments.

Punishment Scale. Subjects made their punishment judgments on a 20-point graphic rating scale whose endpoints were defined by special end-anchor stimuli. The high end anchor included a display of 12 (or 20) ink-smeared stamps, the culpa information (accompanied by a line drawing) that "He was jealous of your fine stamp collection and wished to destroy it. Suddenly, he poured ink on your stamps," and the statement that no recompense was given. The low end anchor included a display of one ink-smeared stamp, the culpa information (accompanied by a line drawing) that "Before he arrived you were alone looking at your stamps. You pushed against your kool-aid and spilt it," 
together with a display of an undamaged stamp given by the other person to repair the loss. Six practice trials from the main design as well as four presentations of each end anchor were given to acquaint the subject with the task.

The foregoing procedure was designed to ensure that subjects used the rating scale as a true linear (equal interval) scale. This procedure has been generally successful in previous work based on functional measurement methodology (Anderson, 1981a, 1982).

Procedure. Following practice, the regular experimental stimuli were read to the subject, using the gender pronoun corresponding to the subject's sex. On each trial, the three pieces of stimulus information were read in the natural order: culpa, damage, and recompense. To help ensure attention to all of the information, the information was then repeated in abbreviated form in the opposite order. The experimental stimuli were presented in a different random order for each subject. Subjects were students at the University of Califomia, San Diego, who served either for pay or to fulfill a course requirement in introductory psychology. There were $20,10,18$, and 10 subjects in the four respective experiments.

\section{EXPERIMENT 1 PARADOXICAL EFFECT OF RECOMPENSE}

The purpose of this experiment was to obtain preliminary information on the integration rules for the three moral variables. In addition to the complete, $3 \times 2$ $\times 3$, Culpa $\times$ Damage $\times$ Recompense design, the corresponding two-factor Culpa $\times$ Damage and Culpa $\times$ Recompense designs were included.

\section{RESULTS}

It is convenient to organize the results around the integration rules for each pair of variables. Each rule will be presented in terms of its factorial graph, for this factorial pattern provides essential clues to the structure of the integration. Following this, a paradoxical effect of the recompense will be noted.

Damage-Culpa Integration. The first question concerns the integration of damage and culpa; the relevant data are in the left panel of Figure 1. The two dashed curves represent the mean judgments of punishment from the two-factor, Damage $\times$ Culpa design. Each curve corresponds to one level of damage, which is listed by the curve, for the three levels of culpa listed on the horizontal axis. These two curves look essentially parallel, and this graphical appearance of parallelism is supported by the nonsignificance of the interaction, $F(2,38)=.04$.

Similarly, the two solid curves in the left panel of Figure 1 represent the corresponding Damage $\times$ Culpa graph, averaged over the recompense factor in the complete three-factor design. Here again the graphical appearance of parallelism is confirmed by the nonsignificance of the interaction, $F(2,38)=.17$. 


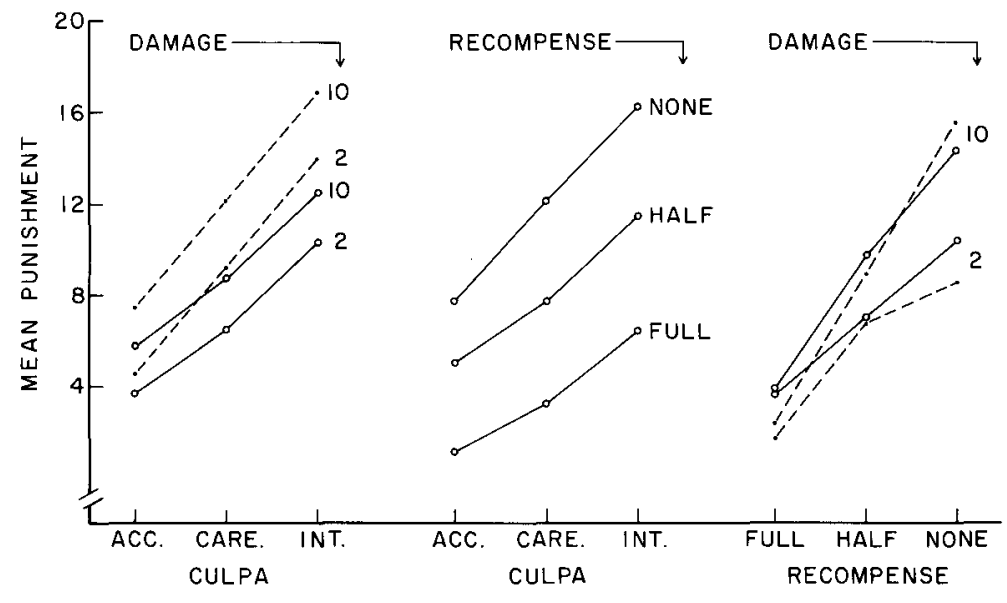

Figure 1. Assigned punishment as a function of culpa, damage, and recompense, Experiment 1. Each panel shows the factorial graph for one pair of moral variables, listed as curve parameter and on the horizontal axis. Solid curves from three-factor design; dashed curves from two-factor designs. (ACC. = accidental; CARE. $=$ careless; INT. = intentional.)

The observed parallelism is important theoretically because it implies that damage and culpa are integrated by an adding-type rule:

$$
\text { Punishment }=\text { Damage }+ \text { Culpa. }
$$

This outcome will be verified repeatedly in the subsequent experiments. These experiments will also take up the issue of whether the adding-type rule is true addition or averaging.

One further theoretical point is brought out by comparison between the dashed and solid curves in the left panel of Figure 1. The fact that they are parallel suggests that the integration of damage and culpa is the same, regardless of whether recompense is specified or not. This implication is important because giving recompense could have ramified effects, changing the effective values of the damage and culpa information and/or changing the rule that governs their integration.

Recompense-Culpa Integration. The Recompense $\times$ Culpa factorial graph in the center panel of Figure 1 is markedly nonparallel, and this graphical appearance is confirmed by the significant interaction term, $F(4,76)=4.56$. Integration of the recompense and culpa information cannot follow an additive rule, therefore, because an additive rule requires parallelism. However, the observed 
pattern of nonparallelism can be accounted for by either a multiplying rule or an averaging rule.

The multiplying interpretation is straightforward: Recompense decreases deserved punishment by a constant proportion. The half curve should therefore be lower than the none curve by a constant percentage at each level of culpa. The same holds for the curve for full recompense. Since the none curve happens to be approximately straight, the half and full curves should also be approximately straight, but with proportionately lower elevations and lower slopes. In short, the three curves should exhibit a linear fan pattern-as they do.

Under the averaging interpretation, the recompense information is processed in basically the same way as the damage and culpa information. To account for nonparallelism with the averaging rule requires an assumption of differential weighting (see Anderson, 1981a). Specifically, the averaging interpretation requires that the slope of each recompense curve be inversely related to its weight. This requires that half recompense has greater weight or importance than none, and that full recompense has greater weight than half, an assumption that is not unreasonable. Since the averaging and multiplying rules can both account for the observed patterns, additional data are needed to discriminate between them. This problem is taken up in Experiment 2.

Damage-Recompense Integration. The right panel of Figure 1 shows the Damage $\times$ Recompense factorial graph. The two dashed curves from the twofactor design are clearly nonparallel, and the interaction was significant, $F(2$, $38)=19.51$. The same diverging pattern appears in the two solid curves from the full three-factor design, and it also showed significant deviations from parallelism, $F(2,38)=15.51$. Like the recompense-culpa integration, therefore, the recompense-damage integration is nonadditive.

The multiplying rule gives a ready explanation of these data. It implies that the factorial graph should have a linear fan shape, and just that shape appears for both designs.

The averaging rule, however, also accounts for these data under the cited assumption that higher levels of recompense have greater weight. Since the averaging model requires the weights to sum to one, the relative weight of damage must decrease at the higher levels of recompense. But the vertical separation between the two damage curves is a direct function of the relative weight of damage, and so they must be closer together at the higher levels of recompense. Thus, the same weighting assumption that enables the averaging model to account for the nonparallelism in the center panel also enables it to account for the nonparallelism in the right panel.

There is one piece of evidence that favors the averaging rule over the multiplying rule. This comes from comparison of the dashed and solid curves in the right panel of Figure 1. The mean slope is less for the solid curves than the dashed curves, $F(2,38)=53.92$, and these two-factor patterns are significantly 
different, as shown by the three-way interaction $F(2,38)=5.88$. Empirically, the difference between the dashed and solid curves results from the integration of the third factor, namely, the culpa information. If a multiplying operation were involved, then the solid curves, having flatter slope, would also have to have lower elevation. As the graph shows, however, the solid curves lie above the dashed curves at five of six data points. That is difficult to account for with a multiplying rule. Moreover, the solid curves cross over the upper dashed curve, which is also contrary to the multiplying rule.

The averaging model provides a complete account of these data patterns. If the culpa information is averaged in, that decreases the relative weight of both recompense and damage information. Since the slopes of the curves are a direct function of the relative weight of recompense, the solid curves should have lower slope. And since the vertical separation of the curves is a direct function of damage, the solid curves should lie closer together, as they do. Moreover, the crossover of the solid and dashed curves is consistent with the averaging rule under the reasonable assumption that the mean culpa value is near the scale midpoint. Thus, all three comparisons between the dashed and solid curves receive a unified interpretation under the averaging hypothesis.

Paradoxical Effect of Recompense. Recompense has a much larger effect than damage, as may be seen in Figure 1 by comparing the left and center panels. The main effect of damage is given by the separation between the two damage curves labeled 2 and 10 in the left panel. Similarly, the main effect of recompense is given by the vertical separation among the curves in the center panel. As can be seen, the effect of recompense is several times larger than the effect of damage. This is paradoxical because the objective value of recompense was not greater than that of damage.

\section{EXPERIMENT 2 AVERAGING RULE FOR RECOMPENSE}

The results of Experiment 1 provided promising evidence for a moral algebra in judgments of punishment. However, the evidence that recompense information was integrated by an averaging rather than a multiplying rule was only suggestive. Moreover, the recompense variable showed an unexpected, paradoxically large effect. The present experiment was designed to obtain firmer evidence on these two issues.

All three two-factor designs were employed in essentially the same way as in the first experiment. In addition, judgments were obtained based on each single piece of information. These designs provide scale-free, crossover tests that discriminate between the averaging and multiplying models. General procedure was the same as in Experiment 1. 


\section{RESULTS}

Three main results were obtained. First, the paradoxical effect of recompense was verified. Second, the two-factor integrations showed the same patterns already found in Experiment 1. Third, the crossover tests supported the averaging rule and ruled out the adding and multiplying rules.

The data are in Figure 2. The solid curves in each panel represent the integration for one pair of information factors. The left panel portrays the Damage $\times$ Culpa integration, with one curve for each number of damaged stamps and with the three levels of culpa on the horizontal. The two solid curves are approximately parallel, $F(2,18)=.04$, replicating the result of Experiment 1 . The two remaining panels of Figure 2 exhibit linear fan patterns like those seen in Experiment 1. In the present experiment, however, the linear fanning was statistically significant only for the Damage $\times$ Recompense graph in the right panel. Comparison of the left and center panels shows that recompense has much larger effect than damage, verifying the paradoxically large effect of recompense observed in Experiment 1.

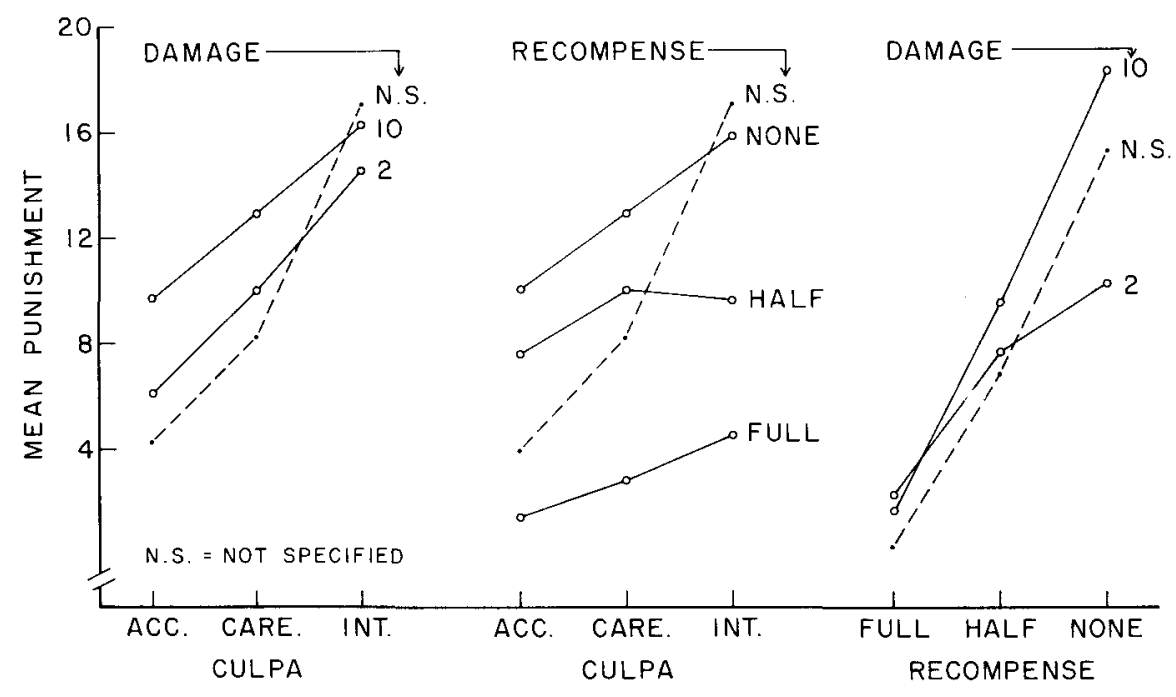

Figure 2. Assigned punishment as a function of culpa, damage, and recompense, Experiment 2. Each panel shows the factorial graph for one two-factor design, with the two moral variables listed as curve parameter and on the horizontal axis. Dashed curves denote response to single moral variable listed on horizontal axis. (ACC. $=$ accidental; CARE. $=$ careless; INT.$=$ intentional. ) 
Evidence for Averaging. The evidence for the averaging rule comes from comparison of the dashed and solid curves in each panel of Figure 2. Each dashed curve represents responses based on only one piece of information. In the left panel, for example, the label N.S. means that damage was not specified, and that the judgment was based on culpa alone. As can be seen, the lower solid curve crosses over the dashed curve. This crossover is contrary to an additive or summation rule, but supports the averaging rule.

Although the logic of this crossover test is well known (see, e.g., Anderson, 1981a), it may be useful to explain how it applies to the present task. In the left panel, both the additive and the averaging rules can account for the parallelism of the solid curves, but only the averaging rule can account for the crossover. To see this, note that the dashed curve represents judgments based on culpa information alone. Comparison of the dashed curve with the solid curve labeled 2 shows what happens when the information that two stamps were damaged is added. If this information had an additive effect, then the solid curve would have to lie entirely on one side of the dashed curve. This prediction does not require that the additive effects be mathematically exact, only that the direction of effect be the same at each point. The crossover thus provides strong evidence against any form of additive model.

Under the averaging hypothesis, the additional information about the two damaged stamps is averaged in with the culpa information. This is the milder level of damage, and may be assumed to have a value around the midpoint of the scale. Since this value is greater than the leftmost point on the dashed curve, averaging it in will raise the response to the lowest level of culpa; and since this value is lower than the rightmost point on the dashed curve, averaging it in will lower the response to the highest level of culpa. In this way, the averaging model accounts for the crossover in the left panel of Figure 2.

In the other two panels of Figure 2, the theoretical issue is to test between the averaging and the multiplying rules. Here again the issue rests on comparison of the dashed and solid curves. The averaging rule provides a straightforward account of the crossover, in accord with the logic illustrated in the preceding paragraph.

The multiplying rule, in contrast, cannot account for these data patterns. This rule requires that the dashed and solid curves form a linear fan with a common point of intersection. But in the center panel, the dashed curve intersects the two solid curves at different elevations, and the solid curves would only intersect if extrapolated to the left. Similarly, in the right panel, the dashed curve intersects the lower solid curve at about half recompense, whereas the two solid curves intersect at about full recompense. These data patterns are therefore sharply inconsistent with the multiplying rule. 
Imputations. A final comment should be added concerning the question of imputations about unspecified information. Imputations are certainly possible. If only culpa is specified, for example, there is some presumption that damage occurred. If the subject made an imputation about damage and averaged that in, it would be the same as if damage had been specified. That would tend to eliminate the crossover in the left panel of Figure 2. Accordingly, the observed crossover indicates that if any such imputations were made, they had rather little influence in these judgments.

The question of imputations becomes central when only recompense is given, in the right panel of Figure 2. Objectively, recompense cannot occur in the absence of damage. On a rational basis, therefore, the subjects could not make a judgment without an implicit inference about damage. Rationally, therefore, the dotted curve should not cross over, but should form part of the fan-like pattern with the dashed curves.

The subjects are not compelled to be rational in this way, of course, and the pattern of data indicates that they are not. Instead, it appears that they attach a value to recompense per se, and make a judgment on that basis, without attempting to integrate an inferred level of damage. This strategy is not entirely unreasonable, for recompense may have a moral value per se, as an indication of a favorable trait of the person. Not too much should be made of one incidental result, but it does illustrate how simple integration experiments can reveal aspects of moral algebra that might otherwise be difficult to uncover. Imputations have been found to be important in other situations and present some interesting problems in cognitive analysis (Anderson, Chapter 2 of Volume I).

\section{EXPERIMENT 3 ORDER INVARIANCE OF INTEGRATION RULES}

This experiment addresses the question of whether the integration process is affected by the order in which the information is presented. This question has special importance because culpa, damage, and recompense seem to be qualitatively different kinds of information. It is somewhat surprising, therefore, that the two previous experiments found evidence for an averaging process because averaging seems to require qualitatively similar information.

It is entircly possible, of course, that all three kinds of information are evaluated in common moral currency and then averaged. It is also possible, however, that the averaging rule obtained in the previous experiments results from some particular processing order adopted by the subjects. In particular, the subjects may have adopted the strategy of beginning with an equal-weight averaging of culpa and damage, and then modifying this judgment by making a unequal-weight subtractive averaging of recompense. 
To study this question, the information was presented in three different sequences, each hypothesized to correspond to a reasonable processing strategy. The sequence, first culpa and damage, then recompense, could be expected to elicit an act-wise information processing, congruent to the natural causal order implicit in this sequence.

The sequence, first culpa and recompense, then damage, could elicit an initial integration of the two "subjective" components, followed by a further integration of the "objective" damage component. In this sequence, recompense might still be averaged, but with equal rather than differential weighting.

Finally, the sequence, first damage and recompense, then culpa, could elicit an initial integration in which recompense acts as a multiplier on the damage. This initial multiplication would be followed by an averaging integration of culpa. Regardless of the plausibility of these particular hypothesized rules, it is clearly advisable to test whether order of presentation affects the generality of the results of Experiments 1 and 2.

Each subject received all three pieces of information in one of the three orders already indicated. In order to crystallize and assess any possible order effects, the subject made an intermediate judgment after the first two pieces of information were presented. The third piece of information was then presented and, to minimize memory loss and inattention, all three pieces of information were repeated in the same order in abbreviated form. Following this repetition, the final judgment was made.

The basic stimulus design was the three-factor, Culpa $\times$ Damage $\times$ Recompense design of Experiment 1. The higher level of damage was changed from 10 to 16 stamps in an (unsuccessful) attempt to increase the main effect of damage. Each subject served in all three sequence conditions, randomly assigned in equal numbers to the six possible permutations of the three sequence conditions. Each sequence condition was preceded by instructions, end anchors, and practice trials, which presented the information in the same order as the sequence condition. General procedure was the same as in Experiments 1 and 2.

\section{RESULTS}

Generality of Integration Rules. The essential results of this experiment can be summarized very simply. The factorial graphs for the intermediate judgments, based on only two pieces of information, had essentially the same form as in the previous experiments. The same was true for the final judgments, based on all three pieces of information. Moreover, the final judgments were essentially unaffected by the order in which the information was presented. The integration rules are the same, therefore, regardless of the amount of information and regardless of its order of presentation. 
Figure 3 presents a detailed view. The two Damage $\times$ Culpa graphs in the left panel are essentially parallel. The intermediate judgments based on only two pieces of information are shown by the dashed curves; the final judgments based on all three pieces of information, but averaged over the recompense factor, are shown by the solid curves. This graphical parallelism was supported by the nonsignificance of the Damage $\times$ Culpa interactions, $F(2,34)=.28$ and .98 for the intermediate and final judgments, respectively.

A similar story holds for the Recompense $\times$ Culpa and the Damage $\times$ Recompense graphs in the center and right panels. These graphs show the pattern already seen in Figures 1 and 2. The divergence from parallelism yielded significant interactions in three of the four cases: $F(4,68)=.67$ and 2.86 for the intermediate and final judgments for Recompense $\times$ Culpa; and $F(2,34)=11.29$ and 16.64 for the intermediate and final judgments for Damage $\times$ Recompense. Moreover, the intermediate and final judgments exhibit the same pattern in each panel of the graph.

The question of uniformity of the integration rules was assessed statistically by employing sequences as a fourth factor in an analysis of variance on the final judgments. If the order of presentation affects the integration rule, that will appear as an interaction between sequence and one or more of the three

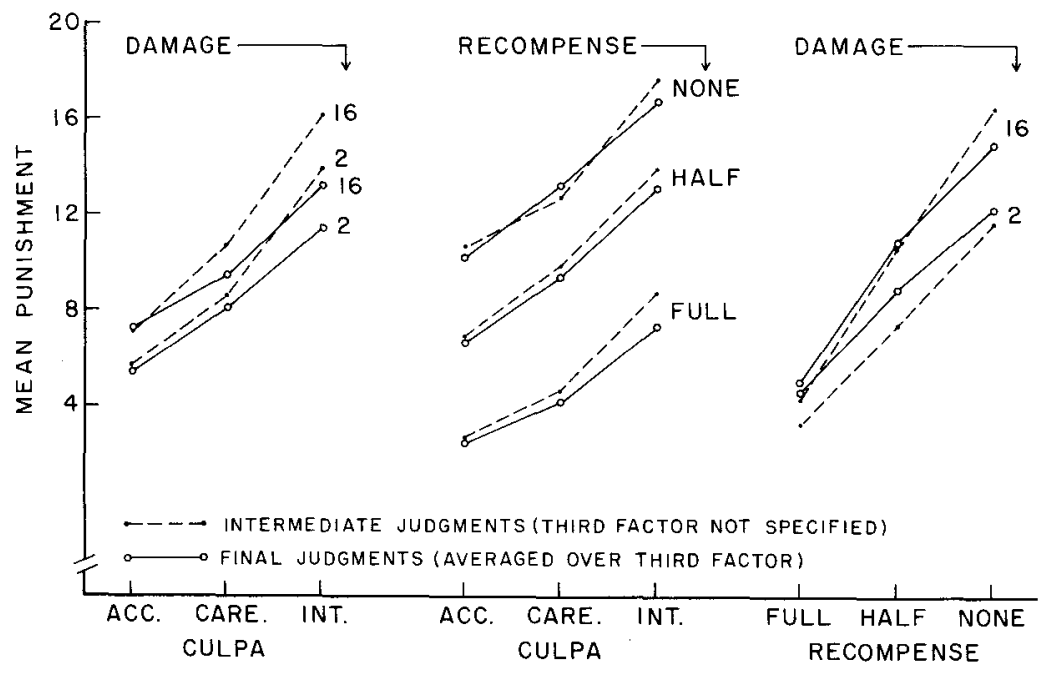

Figure 3. Assigned punishment as a function of culpa, damage, and recompense, Experiment 3. Each panel shows the factorial graph for one pair of moral variables, listed as curve parameter and on the horizontal axis. (ACC. $=$ accidental; CARE. $=$ careless; INT. = intentional.) 
information factors. None of these interactions was significant. There was a main effect of sequences, $F(2,34)=4.73$, with the highest judgments of punishment in the culpa-damage-recompense sequence, and the lowest judgments in the culpa-recompense-damage sequence. The reasons for this effect are not clear, but it only pertains to the overall level of judgment, not to the pattern. Thus, it requires no qualification on the uniformity of the integration rules. Further evidence that order of presentation does not affect the integration rule has been obtained by Grueneich (1982) and Surber (1982).

Paradoxical Recompense Effect. The data of Figure 3 corroborate the two previous experiments in finding an extremely large effect of recompense. Comparison of the vertical spread of the left and center panels shows that recompense has approximately four times the effect of damage. This comparison seems paradoxical because the objective value of recompense was not larger than the value of damage.

Furthermore, recompense has approximately twice the effect of culpa, as may be seen from inspection of the Recompense $\times$ Culpa graph in the center panel. This suggests that the large recompense effect cannot be explained merely by considering recompense in subjective rather than objective terms, because the culpa variable is entirely subjective and covers a large range, from accident to intentional malice.

Theoretical implications of this recompense effect will be taken up in the discussion. Here it is noted that the averaging model provides two implications about what is going on. Both relate to the two-parameter representation of the averaging model, according to which the effect of each variable depends on both its weight and on its range of scale values.

The first implication concerns the small effect of damage. This does not mean that subjects consider that damaging 2 stamps is almost as bad as damaging 16 stamps. The badness values of these two deeds are quite different; but for assigning punishment, subjects attach low weight to the damage variable.

This implication follows from comparison of the solid and dashed curves in Figures 1 and 3. In each panel, the solid curves differ from the dashed curves by the addition of a third piece of information, which the preceding results have shown to be integrated by the averaging rule. The averaging rule requires the solid curves to have flatter slope than the dashed curves in direct proportion to the weight of the additional information, regardless of its scale value. Similarly, the averaging rule requires the solid curves to lie closer together than the dashed curves in direct proportion to the weight of the additional information, regardless of its scale value.

To apply this theoretical rationale, note that the solid curves are flatter and closer together in the left panels of Figure 1 and 3. That implies that the added recompense information has substantial weight. In the right panels, similar reasoning shows that the added culpa information has substantial weight. But in 
the center panel of Figure 3, the solid and dashed curves have approximately equal slope and equal vertical spread. It follows that the additional damage information has relatively small weight.

But as already noted, the actual observed effect of any piece of information depends both on its scale value and on its weight. The small effect of damage is thus a result of its small weight. It would be incorrect to conclude that badness value is not much different for low and high damage. On the contrary, since the weight is small, the badness values must be quite different to account for the observed effect.

Similar reasoning applies to the comparison of recompense and culpa. The mean vertical separation of the two dashed curves is less in the left panels than in the right panels of Figures 1 and 3. Since the damage factor is the same in both, it follows that culpa has somewhat greater weight than recompense. It follows, therefore, that recompense must have substantially greater range of scale value than culpa in order to account for its larger observed effect.

\section{EXPERIMENT 4 TWO COMPONENTS OF RECOMPENSE}

The operation of recompense in judgments of deserved punishment seems straightforward: The punishment should fit the crime. Since recompense reduces the harm, it should reduce the punishment. This effect has its locus in the victim.

But, recompense has a second component, which has its locus in the offender. Voluntary recompense confers a positive moral benefit on the offender, thereby decreasing culpa and hence also punishment. Involuntary recompense serves as punishment, which subtracts from the total deserved punishment to yield the assigned punishment.

This experiment presents an initial study of the two components of recompense just considered. The main hypothesis was that recompense and culpa should exhibit an interactive effect that relates to the nonadditivity previously observed in the integration rule. The design was the same as the three-factor design of Experiment 1, except that the level of half recompense was replaced by the information that "The insurance paid back for all of the ruined stamps."

\section{RESULTS AND DISCUSSION}

The essential results are shown in the Recompense $\times$ Culpa graph of Figure 4 . The top and bottom curves represent the same conditions studied in the preceding experiments and they show the same nonadditivity, which is reflected in the nonparallelism. 
Figure 4. Assigned punishment as a function of culpa and recompense, Experiment 4. (ACC. = accidental; CARE. = careless; INT. $=$ intentional. $)$

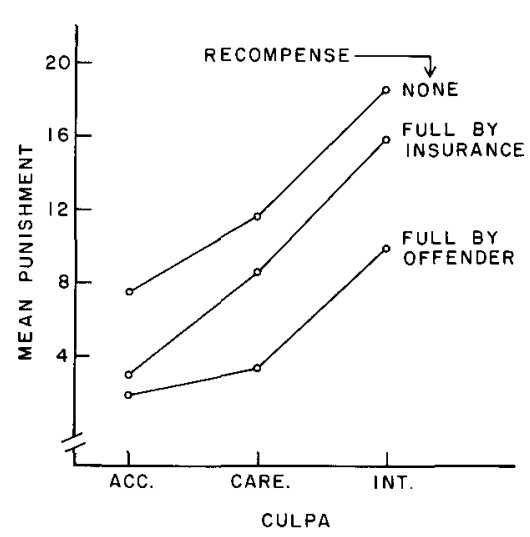

The difference between the top and middle curves is considered to represent the effect of the first component of recompense, namely, that associated with the harm to the victim. Similarly, the difference between the middle and bottom curves is considered to represent the second component of recompense, namely, that associated with the offender.

Main interest is on the comparison of the two lower curves, which represent complete recompense, either by the insurance or by the offender. These two curves show the hypothesized interaction. When the damage was accidental, at the left of the graph, it makes little difference whether the recompense was given by the offender or by the insurance.

With careless or intentional damage, however, more punishment is assigned when the compensation is made by insurance. This effect was significant, as shown by the interaction term for these two curves, $F(2,18)=7.33$.

This interaction is as expected from the hypothesis of two components of recompense. For accidental damage, there is one main component, namely, that associated with the harm to the victim. Given full recompense, its source is mainly immaterial for the assignment of punishment.

In contrast, careless and intentional damage carry two components, one associated with the damage itself, the other associated with the harmful action. Indeed, the present data suggest that the latter component may be the more important since the middle curve is closer to the top curve than to the bottom curve. This two-component interpretation will produce nonparallelism by virtue of differential weighting, since the second component adds more weight. The present data, of course, do not rule out an effect of the second component on the net value of the recompense.

An incidental result is that judged punishment is reduced by insurance compensation even when the damage is accidental. In this case, the offender is held responsible to some degree even when the net damage is zero. This may seem 
contrary to justice, but it should be kept in mind that the term accidental is only a label for an experimental manipulation, and does not necessarily remove the implication that care and foresight could have avoided the damage. Results by Leon (1980) point to social learning, since it was mainly the youngest children in his study who discounted damage when it was accidental.

\section{GENERAL DISCUSSION}

Three topics are considered in this discussion. The first is a brief review of the present and related results on moral algebra. The second concerns the structure of recompense. The third and final topic considers moral algebra in the law.

\section{MORAL ALGEBRA}

The results of all the experiments support the hypothesis that judgments of deserved punishment obey a moral algebra. These results agree with previous work on intent-damage integration and extend it to include the factor of recompense. Two integration rules, as well as certain questions of generality, require consideration.

Averaging of Culpa and Damage. The two moral variables, culpa and damage, obeyed an equal-weight averaging rule. The parallelism pattern of the Culpa $\times$ Damage graphs in Experiments $1-3$ points to one of two integration rules: adding or averaging. The adding-averaging question was resolved by inclusion of scale-free tests, especially in Experiment 2. These scale-free tests ruled out the adding rule and supported the averaging rule.

These results support and extend work by Leon $(1976,1980)$ and Surber (1977, 1982), who also found evidence for averaging of culpa and damage. The present results show the same averaging rule when the third variable of recompense is also specified. This integration, moreover, was the same regardless of the order in which the three moral variables were presented.

These extensions of previous work are important because they point to the generality of moral integration rules. Results obtained with simple information fields may thus hold for more complex fields. Further work, especially in more natural situations, is needed to assess the scope and limits of rule generality.

Two exceptions to the averaging rule in previous work require comment. A number of Leon's (1980) subjects followed the averaging rule except when the action was accidental, in which case damage was excluded from the integration. This accident-configural rule was fairly frequent among the youngest children, although infrequent among adults. According to Leon's interpretation, older subjects may assign definite culpa value even for accidents. Older subjects could, in particular, hold the actor responsible for accidents that resulted from 
lack of prudence or foresight, whereas younger children might well be less demanding in this regard. A remarkable later result (Leon, 1984) found mother-son similarity for this accident-configural rule.

Surber (1977) found nonparallelism in her second experiment, which might seem to disagree with the averaging rule. However, inspection of her data (Figure 3, p. 661) shows parallelism separately for damage and for favorable outcomes. The nonparallelism resides in the comparison between harmful and favorable outcomes. This pattern of nonparallelism agrees with the averaging rule under the assumption that damage has greater importance than favorable outcome. This interpretation is consistent with the substantial literature on negativity effects in social judgment, beginning with Anderson (1965) and Lampel and Anderson (1968). It is also consistent with the parallelism obtained by Lane and Anderson (1976) for judgments of gratitude based on intent and favorable outcomes.

Nonadditive Averaging of Recompense. The factorial graphs for recompense showed nonparallelism, both for recompense-damage integration and for recompense-culpa integration. The observed pattern of interaction could be accounted for either by the multiplying rule or by the averaging rule with differential weighting. The scale-free tests of Experiment 2 infirmed the multiplying rule and supported the averaging rule.

The pattern of nonparallelism for integration of recompense implied that the importance or weight parameter was higher for greater levels of recompense. Thus, full recompense not only had higher scale value than half recompense, but also greater importance.

Overall, the results point to the operation of a general averaging rule for judgments of punishment. This rule has equal weighting within the damage and culpa dimensions, and differential weighting within the recompense dimension. This, together with other results, suggests that recompense effects may be mediated through other moral categories, as indicated in the later discussion of structure of recompense.

Recompense in Judgments by Children. Data consistent with the integration rules found here with adults have been observed with children (Hommers \& Anderson, 1985). For children, as for adults, culpa and damage may be integrated by equal-weight averaging, whereas recompense appears to be integrated with both culpa and damage by nonadditive averaging, that is, averaging with differential weighting. Cross-cultural generality was shown by Hommers (1985, 1986c), who found similar results for children and adults in Germany. Integration rules thus appear age-invariant down to 4 years.

Developmental trends were found, however, in moral values. Most notable was an accentuation at younger ages of the paradoxical outcome that recompense had far greater effects than the damage for which recompense was made. 
Damage, on the other hand, had smaller effects at younger ages. Methodological checks indicated that these developmental changes were real.

This pattern of value development disagrees with the traditional objectivesubjective characterization that younger children show greater sensitivity to objective factors, such as damage. Nevertheless, this pattern is consistent with the fairness studies of Anderson and Butzin (1978), who found that the subjective factor of need had at least as much effect as the objective factor of deed. The paradoxical effect may, of course, be peculiar to the present stamp scenario, in which recompense includes both objective and subjective components. Further tests with purely subjective recompense are thus desirable. The problem of comparing importance of objective and subjective factors, already mentioned, may be solvable with recent developments in estimation theory for the averaging model (Zalinski \& Anderson, Volume I, Chapter 10).

The paradoxical effect of recompense was accentuated in preschoolers studied by Hommers (1986b), who rated half-recompense with a large number of damaged stamps better than half-recompense for a small number of damaged stamps. With older children and adults, similar inversion was observed only for full-recompense and double-recompense (see similarly Hommers, 1988d). Such disordinal patterns of data can be accounted for by the averaging model with differential weighting. This moral algebra thus provides a base for measurement of developmental trends in weighting that could not be determined with other methods.

Social Reality. Moral algebra is considered to provide a general foundation for everyday moral judgment and behavior. One basis for this statement lies in the generality of the integration rules just discussed. A second basis lies in the similarity of results in the moral and extra-moral domains, for the present moral algebra mirrors the cognitive algebra previously found in diverse areas of social judgment, including person cognition, causal attribution, fairness, social attitudes, and marriage (see Anderson, 1981a,b). Moral judgment, accordingly, is considered to have the same cognitive structure and obey the same cognitive processes found in these other areas of social cognition. Moral judgment thus becomes part of a unified, general theory.

Unified theory may seem unlikely in view of the obvious complexity of everyday morality. Unified theory is possible, however, through a focus on deeper levels of processing. Everyday morality is complex because moral values are extremely sensitive to the particular social situation. The further dependence of values on the individual and individual-role interactions with the social situation increase the complexity. Nowhere are individual differences greater than in moral values, and nowhere are situational effects greater. Theory construction requires an approach that can allow for such value complexity in terms of process simplicity. 
Integration theory allows and indeed insists that values are sensitive to individual and situation. The rules for integrating these values, in contrast, are considered to have substantial invariance. This rule invariance provides a theoretical foundation for value analysis by means of functional measurement methodology. Functional values that are operative in given individuals and in particular situations can thus be assessed. The complexity of everyday morality, far from being an objection to moral algebra, testifies to its unique power.

Phenomenology and Experiment. Moral algebra is not just an end in itself. It also provides a basis for unifying the phenomenological and experimental approaches. Potential for unification appears in the dual qualitative-quantitative nature of an algebraic integration rule. The qualitative aspect appears in the concepts specified in the rule. The concept of culpa, for example, is taken from common language and phenomenology, but that does not guarantee that it represents a cognitive entity. Finding that culpa obeys an exact algebra confers some measure of construct validity. The quantitative precision of moral algebra thus has qualitative value for assessing cognitive reality.

The precision of cognitive algebra can also provide validity criteria for phenomenological analysis. Consciousness can provide priceless cues about cognitive process, but validity assessment is essential, as shown by the many failures of the phenomenological method. Reliance on subjects' verbal reports has repeatedly led to misconceptions, as with Piaget's ill-fated centration hypothesis, which originated in his studies of moral judgment (see also Anderson, Volume III, Chapter 5). Cognitive algebra can provide such validity criteria. More important, cognitive algebra can provide a foundation for experimental validation of phenomenological methodology.

\section{STRUCTURE OF RECOMPENSE}

Recompense is psychologically complex. Further work requires a more general conceptual framework than was needed in the foregoing experiments. The blame schema (Anderson, 1976; this volume, Chapter 6) provides a useful framework for thinking about recompense, as illustrated in the following structural analysis. Among the implications of this analysis of the blame schema are first, that recompense needs to be studied as one member of the class of blamereducing informers, and, second, that retributional punishment needs to be treated as one form of recompense. Although this usage may seem odd, it agrees with the dictionary definitions for both English and German (recompense = Wiedergutmachung), and it seems necessary for a unified treatment.

Blame Schema and Blame-Reducing Variables. The blame schema, which is taken from everyday life, specifies deserved blame as a joint function of the damage, or outcome, of some action and the culpa, or social responsibility, for the action. Symbolically, 


\section{Blame $=$ Culpa $\oplus$ Damage.}

Here $\oplus$ is an integration schema, which, as the present results indicate, assumes the form of an averaging rule under fairly general conditions. For present purposes, however, the exact form of $\oplus$ is not of concern. What is of present concern is that recompense can act through each of the three terms of this schema. Each term represents one mode of reducing blame.

The primary locus of reparational recompense is the damage term, as illustrated in the present stamp experiments. However, recompense may also operate through the other two terms of the blame schema. Voluntary recompense, for example, confers positive moral value, and so reduces culpa, or responsibility. Voluntary recompense also implies some acceptance of blame, and so, by the principle of due measure, reduces the amount of additional deserved blame. In this way, as indicated previously, recompense appears to operate through other moral categories.

It is desirable, therefore, to amplify the discussion of the blame schema to consider recompense within the larger class of blame-reducing stimuli. This may help avoid neglect of moral variables that are related to recompense or that contain some component of recompense. Each of the three terms of the schema may be reconsidered in this way.

With regard to the damage term, three kinds of harm must be considered: material damage, personal injury, and mental suffering (e.g., ego-injury, grief, resentment). Recompense in the form of reparation can, accordingly, take many forms. Exact reparation, as in the present stamp scenario, is convenient experimentally but unusual socially. Material compensation typically involves some different good, especially money or gifts. Nonmaterial recompense, such as apology, which has a primary function of ameliorating insult or injury, may also serve in lieu of material recompense. In addition, blame may be given for wrong acts for which there is no victim or even any specifiable damage (Anderson, this volume, Chapter 6 ). In this case, recompense may take the form of symbolic undoing of the wrong act, as by promising not to do it again.

A second locus for blame reduction is the blame term itself. Loss and suffering by the offender, for example, are often viewed as retribution, which, by the principle of due measure, reduces blame and deserved punishment. Loss and suffering may thus be considered a form of recompense. Apology may similarly be a form of recompense. Forced apology may constitute disagreeable retribution, whereas free apology may constitute some acceptance of blame that reduces further deserved blame and punishment.

Variables that affect the blame term may also affect culpa. Free apology, for example, may reduce culpa by reducing an implied malicious intent. Repentance and remorse seem to include a component of apology that acts in much the same manner. 
The blame schema has a general role in everyday morality. Virtually all social relations are pervaded by blame, whereas punishment depends on relations of authority or power. Blame is common in marriage, for example, and in diverse other social groups in which one would not ordinarily speak of punishment. Moreover, blame appears to underlie the recompense function of punishment. The blame schema thus appears to offer a useful organizing principle for moral judgment with considerable analytical power.

Harmdoer-Victim Duality. A basic duality in the concept of recompense appears in the dual roles of harmdoer and victim. Recompense has separate components that correspond to harmdoer and victim, or more generally, to the actor and the action.

One component is undoing the harm-this is the explicit function of recompense. Reducing harm, as the blame schema shows, acts directly to reduce deserved punishment.

The actor component is really two components, the first of which involves retribution. A person who makes reparation presumably suffers by doing so, whether from material loss or from self-humbling. This suffering constitutes a form of punishment, which subtracts from the punishment deserved for the original action.

In addition, recompense may confer positive moral value. At least when it is voluntary, recompense implies repentance and partial disavowal of the harmful act. This positive moral information about the actor is integrated into the culpa term, thereby reducing the judgment of deserved punishment.

The conception of separate harmdoer and victim components of recompense has been empirically fruitful in several studies (Hommers, 1988a,b, 1989) in which the harmdoer component was operationalized as apology and the victim component was specified by third-party compensation to separate it from the harmdoer component. Apology had strong effects but showed no age trend from kindergarten to adult. This result included mentally retarded adults, whose judgments were like those of normal adults in all respects. Third-party compensation was nearly as effective as apology but its effects decreased with age. These results indicate that the present age decrease in effect of recompense may be attributed to the compensation component.

Expiation and Reciprocity. Recompense and punishment should fit the offense, not merely in quantitative proportion, but also in quality. This was a prominent theme in Rousseau's views on education, as in his Emile (1978). This theme also appears in Piaget's (1932/1965) investigations of children's understanding of punishment, which concluded that there was a trend from expiation to reciprocity, that is, in his terms, from punishment of arbitrary quality to punishment of a quality in some manner fitting to the offense. Piaget's conclusion, however, does not follow from his data, due to defects in his method. 
These defects may be illustrated with Piaget's story of the boy who played ball in his room, against his father's orders, and broke a window pane. The subject was asked which punishment was fairer: (1) to leave the window unmended for several days so that (it being winter) the boy cannot play in his room; (2) to make the boy pay for the window; (3) to deprive the boy of toys for a whole week. But these three punishments obviously differ not simply in expiationversus-reciprocity, but also in severity and in meaningfulness. This confounding invalidates Piaget's argument.

It may be added that Piaget's stories seem to further confound both severity and meaningfulness with age. Paying for the broken pane could seem severe punishment to a 12-year-old, to whom money could be important, but much less meaningful to many 6-year-olds. Deprivation of toys might well show the opposite confounding. Such confounding invalidates the developmental comparisons made by Piaget.

Indeed, Piaget's investigations led to serious misunderstanding of moral development (see Anderson, Volume III, Chapter 5). Furthermore, children even younger than those studied by Piaget exhibit great sensitivity to recompense (Hommers, 1986b,c; Hommers \& Anderson, 1985). This suggests that they would consider recompense desirable in Piaget's task of choosing fitting punishment, although a more direct test would be required to verify this.

To be sure, there may be a developmental trend towards preference for punishment that fits the offense in quality as well as in degree. Such a trend must be expected simply because judgment of fittingness requires an additional, more complex cognitive operation, and so would necessarily develop later. Present results suggest that fittingness will influence judged punishment as soon as fittingness can be understood.

Stimulus and Response Modes. Recompense may be studied in two quite different modes: as stimulus or as response. In the stimulus mode, which was used in the present experiments, recompense is specified as part of the given stimulus information. The stimulus mode is potentially complex, for it may involve all three components of the blame schema. It has the advantage, however, that each component is subject to separate manipulation. In Experiment 4, for example, the insurance manipulation separated the harmdoer and victim components. Such stimulus manipulation provides leverage for determining the component structure of the overall response.

In the response mode, the amount and/or kind of recompense is adjusted by the subject. Most studies using the response mode have followed Piaget in using a choice task (e.g., Brandt \& Strattner-Gregory, 1980; Shultz, Wright, \& Schleifer, 1986). The choice task, unfortunately, is generally ineffectual for cognitive analysis (see Wilkening \& Anderson, Volume III, Chapter 2). 
With a quantitative response, Hommers (1986a, 1988d) found multi-modal distributions of restitution as a function of victim's fault and harmdoer's fault. This points to individual differences in the unusual form of discrete ideals about restitution that deserves elucidation. These distributions differed for American and German subjects (Hommers, 1988d), moreover, which suggests that such distinct ideals are socio-cultural products. These results disagree with modern equity theory of justice (Walster, Walster, \& Berscheid, 1978), but are consistent with the implicit dependency structure specified in the principle of multiple restitution in the ancient laws, such as the Book of the Covenant (Exodus, 21-22) and the Hammurabic Code (see Hommers, 1983b, 1988d for more detail on the history of recompense).

The response mode has the advantage that it may eliminate the moral component associated with voluntary recompense, thereby simplifying the analysis. Also, it facilitates comparison of different kinds of recompense in terms of their fittingness to the action. A major problem with recompense in the response mode is that it would typically be confounded with retributional punishment. In the present experiments, for example, subjects assigned nonzero punishment even with full recompense, which indicates that their response included a retributional component. An attractive way to attack this problem is with the duplex response technique.

Duplex Response Technique. Help in unraveling the structure of recompense may come from the duplex response technique, in which the subject responds on two dimensions simultaneously. With the present stamp scenario, for example, the subject could be asked: (a) how many stamps the offender should pay back; and (b) how much of some other punishment should be given. The first judgment uses recompense in the response mode to undo the material damage. The second judgment allows for additional retributional punishment.

This example reflects the harmdoer-victim duality already noted. One reaction to a harmful act is to undo or ameliorate the harm. The other is to admonish or punish the offender. Duplex response technique provides some separation of these two reactions along the two response scales. The recompense itself has two components, of course, for the loss of the stamps would be punishment for the offender. Something like the insurance manipulation of Experiment 4 might be able to separate these two components and assess such variables as intention and remorse along the punishment scale itself.

Duplex response technique extends to situations in which exact recompense is not feasible. A cherished possession, for example, may be irreplaceable, but its loss may be ameliorated with sympathy or money. Personal injury and mental suffering can also be partly compensated with sympathy, money, or with revenge. This is recognized in the law, which may award monetary recompense for mental suffering. Such awards rely on assessments of suffering and on money/suffering tradeoffs that deserve study. 
How far mental suffering is recognized in everyday judgments is uncertain. In the present stamp scenario, for example, the victim may be presumed to suffer, but whether this was a factor in the judgments is unknown. One question concerns the effect of giving explicit information about mental suffering. Another is whether imputations are made when such information is not explicitly given, a topic discussed in a subsection of Experiment 2 (see also Singh, this volume, Chapter 4). Both questions have developmental interest.

A related use of duplex response technique is discussed by Anderson and Verdi (1984) for analysis of moral conflict. In moral conflict, the various alternative actions all generally have some right on their side; otherwise there would be no conflict. Duplex response can portray such conflict exactly, whereas a single net response, although often necessary in social action, would miss the essence of the conflict. The technique can be extended to allow a separate duplex scale to represent the rights and wrongs of each alternative action. Duplex response thus has interesting potential for the study of moral judgment.

The importance of duplex response technique was demonstrated by Hommers and Endres (1988), who obtained duplex judgments of restitution and punishment for given combinations of harmdoer's fault (inadvertent or intentional) and victim's fault (contributory negligence or not). The most interesting result was that victim's fault had essentially no effect on the punishment judgment but strong effects on the restitution judgment. Victim's fault thus had quite different importance for the two components of the duplex response, which are confounded in the standard one-dimensional response. In addition, overrestitution for intentional harm was drastically reduced relative to corresponding data with standard univariate response. Further empirical applications of duplex response technique should thus help in analysis of moral judgment.

Recompense and Prevention. Recompense is one means of social control, but it operates differently in different social contexts. A general treatment of recompense thus requires consideration of social context and of social sanctions. This complex field is beyond the scope of this chapter, but a few comments may help point towards a more general conceptual framework.

The two main social functions of sanctions relate to prevention of future harm and recompense for past harm. For prevention of future harm, the main concern is effectiveness: to choose sanctions that will indeed prevent. Recompense for past harm, on the other hand, is mainly concerned with justice. Justice includes reparation to the victim and retribution to the offender. Retribution may well serve a deterrent function, of course, and may even provide affective catharsis for the retributors. But retribution, like reparation, also has a primary function of recompense by suffering. Retributional punishment may thus, from the offender's standpoint, be considered expiation or atonement, a form of moral recompense. 
This moral function of retribution may be demonstrated by considering a person who is guilty of some past offense whose recurrence is not in question, as in war-time atrocities. Most people would feel unsatisfied that such a person should go free or that his punishment should be rationalized as no more than a warning to other potential offenders. Instead, most people would feel that the offense represents a fracture of justice, a moral debt that has to be balanced by expiational suffering. Such moral accounting thus serves the two-fold purpose of conferring justice on the social system and of providing a possibility for moral rehabilitation of the offender who has "paid his debt to society."

\section{LAW AND MORAL ALGEBRA}

Few social institutions are so much bound up with information integration as legal judgment and decision. Legal judgments of all kinds, including juror judgments, judges' bail setting and sentencing, disciplinary actions of wardens, decisions of parole boards, even daily activities of police officers, all depend on processing of evidence. The judge, using that term in a generic sense, sees various pieces of evidence that have to be evaluated and integrated to form an overall judgment. The two basic operations of the theory of information integration, namely, valuation and integration, are thus also basic to judgment and decision in the legal systems of society.

Because of this commonality, legal thought may have heuristic value for cognitive science (Hommers, 1988c; Hommers \& Anderson, 1989). The legal thought of today embodies the thinking of generations of legal scholars, and constitutes a highly developed albeit complex system of knowledge that has an active role in the operation of society. Lawyers and judges must become experts in the understanding and use of this system of knowledge. Their own cognitive processes are highly structured and so of direct interest to psychological science as implicit theories of morality and justice.

Integration. Two algebraic schemas that deal with recompense have been put forward by legal scholars. Von Linstow (1974) proposed a formula with 15 variables for calculating punishment of traffic violators that may be summarized in the form,

Deserved Punishment $=($ Culpa + Damage $) \times$ Recompense,

with $0.8<$ Recompense $<1.0$. Recompense thus yields a proportional reduction of deserved punishment, with no recompense having a formula value of 1 and hence no reduction. This may be called Schema $M$, since recompense acts by multiplication.

In Schema $S$, recompense acts by subtraction:

Deserved Punishment $=$ Culpa + Damage - Recompense . 
This schema is in line with paragraph 46 of the 1975 Penal Code of the Federal Republic of Germany. According to Maurach, Gössel, and Zipf (1978), two components of sentencing are distinguished: harmdoer and act, which correspond to culpa and damage. Recompense is considered to affect both components: It diminishes the damage caused by the act and it raises the moral character of the harmdoer, thereby diminishing culpa. The concept of mitigating circumstances of the British Court of Appeal Criminal Division (Thomas, 1970) seems to embody a similar idea.

The existence of different proposed legal schemas raises two questions. First is the prescriptive question: Which schema ought the judge to follow? As a prescriptive rule, Von Linstow's formula has been criticized by legal scholars (e.g., Bruns, 1974, 1980; Zipf, 1977), but this question lies outside the present discussion. Second is the descriptive or cognitive question: Which, if either, schema do judges actually follow? This question has practical relevance both to judges, whose practice rests on their schemas, and to laypersons, who suffer their sentences.

Progress on the cognitive question is possible with the concepts and methods illustrated in the foregoing experiments. These results point to a nonadditive version of Schema $S$ with laypersons. What is needed is replication with experts, using scenarios more relevant to criminal law. This would be theoretically straightforward within the present approach. Such studies would have great social interest because of their potential for revealing the cognitive processes of the experts.

Valuation. Valuation is prerequisite to operation of an integration schema for legal judgment. The value of culpa in Schemas $M$ and $S$, for example, must be determined before the schema can be applied. Valuation is a matter of expert judgment and is sensitive to the particulars of the context and situation. Much of legal training is aimed at developing expert knowledge systems for valuation, as illustrated in the discussion of responsibility by Hart and Honore (1959).

Value analysis seems to adhere to a prescriptive ideal in legal thinking, in which judgment should be independent of the judge. This prescriptive ideal appears in determinate sentencing systems (Von Hirsch, Knapp, \& Tonry, 1987), for example, which seek to reduce values to an objective standard to make judges' sentences more uniform. But this prescriptive ideal is only partly realizable, as is indicated by divided court decisions and in the problem of disparity of sentences across judges, which presumably arise because judges differ in their personal values and weights for the same evidence. Indeed, some allowance for personal values may be built into the legal system, as with sentencing ranges within which the judge has explicit discretion. In the last analysis, moreover, the ideal prescriptive values arise from and embody psychological values. 
Accordingly, no theory of legal judgment can be complete without capability for measuring personal values. Cognitive algebra provides a unique approach that can solve this valuation problem at the same time that it determines the operative integration schema. Integration schemas may thus be transformed from qualitative verbalisms with unquantified symbols into quantitative laws of cognition with quantified moral values. This capability opens up a new horizon for both cognitive and prescriptive aspects of legal thinking.

Nonadditive Moral Algebra in Legal Thought. The present approach leads to the hypothesis that law embodies a moral algebra, as has been illustrated with the foregoing treatment of recompense schemas. In the law, moreover, recompense has different functions that relate to the two-fold structure of civil and criminal sanctions.

The civil law is intended to rectify injustice by restoring injured rights. The first concern is to provide justice for the victim. The operation of moral algebra may be seen in the complicated rules developed by jurists for calculating distribution of damage over several involved parties. Such recompense, however, may also contain a punitive element, as with awards for multiple damages in modern law or in the prescription of the Judaic code that four sheep shall be repaid for one stolen sheep (Exodus, 22:1).

The criminal law, on the other hand, focuses on the harmdoer rather than the injured party. In this case, the two main functions of recompense are retribution and reparation, both of which relate to the blame schema in the manner already indicated. This appears in the rules and normative theories that jurists have developed about considering recompense when sentencing, as in the notions of Strafzumessungserwägungen and Strafzumessungstatsachen in German law (Bruns, 1974).

More detailed analysis of the moral algebra of law must address the problem of nonadditivity. Although additivity held for culpa-damage integration, nonadditivity was prominent in the foregoing experiments on recompense, and it appears to be a major characteristic of the more general concepts of mitigation and aggravation. For illustration, it is worth detailing the formula for the Minnesota determinate sentencing act (Tonry, 1981). The two main determinants are seriousness of offense and prior record, both intended to be assessed in objective terms. The values of these two determinants constitute the rows and columns of a factorial-type matrix, and the cells of the matrix specify the standard sentence for given values of row and column. The sentence for Aggravated Robbery, for example, varies from 24 to 97 months as a function of prior record. Inspection of the matrix shows it is nonadditive in the specified metric of sentence duration. An additional source of nonadditivity may arise from the discretion allowed the judge to take account of mitigating/aggravating circumstances, which is plus-or-minus a number of months specified separately for each cell of the matrix, the range of discretion being greater for more severe 
sentences. Similar considerations apply to the sentencing matrixes for Washington, DC and Pennsylvania (Von Hirsch, Knapp, \& Tonry, 1987, Appendix, pp. 183, 186-187). This mitigation-aggravation factor may be viewed as a third dimension of the sentencing matrix but its algebraic role is partly dependent on the personal discretion of each judge. This question needs empirical study with judges' actual sentences.

\section{EMPIRICAL ANALYSIS OF LEGAL SCHEMAS}

Cognitive theory of judgment and decision in legal settings requires experimental analysis. Previous work on legal decision has generally relied on phenomenological observation or on statistical methods based on aggregates of cases. Phenomenological observation can be invaluable, but is notoriously fallible. Standard statistical methods can be useful for practical prediction, but have little value for cognitive analysis. This section discusses an experimental approach, personal design, that can solve certain problems of experimental analysis in the natural settings of legal practice.

Observational Analysis. A natural approach to the study of moral algebra in the law is through analysis of actual cases. This may be done phenomenologically, with a focus on single cases, following the case tradition of Anglo-Saxon law. Indeed, judges' opinions constitute a phenomenological data base, for they reflect judges' valuation and integration processes.

This is the natural place to begin the study of judicial judgment-decision. For psychological analysis, it would be important to supplement judges' written opinions with in-depth interviews to reduce ambiguity and incompleteness in the written record. Such phenomenological reports can provide priceless information about cognitive processes, especially about background knowledge developed through extended legal experience.

Judges' opinions are self-report data, and so must be expected to suffer the same limitations and pitfalls found with self-report data throughout psychology. An example appears in Bauer's (1984) study of sentencing by German judges in traffic cases. Although length of sentence had a high correlation with the facts of the case, the written justifications were largely stereotypic commonplaces that had little relation to length of sentence. In the present approach, however, these phenomenological data are not ends in themselves, but rather a beginning for experimental analysis. The problem is to find some way to embed experimental analysis of cognitive process within realistic settings.

Multiple Regression-Correlation Analysis. In legal psychology, the statistical approach of linear regression-correlation models is widely used, as illustrated in the field studies of bail setting and sentencing reported by Konečni and Ebbesen (1982). This statistical approach depends on aggregating many cases, each coded in terms of pertinent variables. Criminal sentences, for example, 
may be coded in terms of severity of sentence, together with such predictor variables as kind and severity of offense, extenuating circumstances, prior offenses, and so forth. Thus coded, the data may be subjected to ordinary multiple regression analysis or to log-linear analysis (e.g., Haberman, 1978), which performs similar functions for qualitative, categorical data.

Such statistical analysis has many uses. Foremost is that it provides a sociological overview of the operation of legal systems that is essential for evaluating how and how well they function. Some of these uses can be seen in the early descriptive approaches to the development of sentencing and parole guidelines (Wilkins, Kress, Gottfredson, Calpin, \& Gelman, 1976), in sociological analyses of criminal sentencing (Myers \& Talarico, 1987), and in evaluation research of sentencing reform (Knapp, 1987), which have relied on linear regression analyses of legal sentencing practice. As Konečni and Ebbesen (1982) and Tonry (1981) have noted, society has little solid knowledge about the functioning of various legal systems, and these investigations raise serious concerns that justice may be systematically unjust.

Unexpected benefits may also be obtained. Thus, an incidental finding in the statistical study of bail setting by Ebbesen and Konečni (1975) was that one or another important information variable was absent in about $35 \%$ of the cases. Similarly, Wilkins et al. (1976) reported that nearly $25 \%$ of the 205 coded items were unavailable in over $25 \%$ of the cases. As pointed out by Anderson (1976, pp. 111-121; 1982, pp. 303-304), this reflects the exigencies of the courtroom situation, and much might be done for justice by the simple device of instituting a standard information schedule for each case.

Nevertheless, the statistical approach has well-known limitations, especially as concerns causal interpretation from correlational data bases. In their study of sentencing, for example, Konečni and Ebbesen (1982) were unable to distinguish two simple and quite different causal models. As another example, it is often claimed that some ethnic or occupational groups are treated more severely than others. If other things were equal, this would indicate the operation of stereotypes and prejudice. But other things are likely to be far from equal. Ethnic groups may differ systematically with respect to prior record, for example, or even age, which can, at best, be only crudely corrected in the statistical model (see also Anderson, 1982, Sections 4.1 and 7.9). Occupational groups, on the other hand, may receive different objective treatment because the judge takes account of retributional damage to their social standing, in accord with the foregoing blame schema.

For psychological theory, therefore, the statistical approach has limited relevance. The valuation and integration operations in the statistical model are unlikely to bear any clear relation to the valuation and integration processes of individual judges. As regards valuation, the statistical approach depends on more or less arbitrary selection and coding of variables, which must then be 
applied uniformly across a heterogeneous mass of cases. The judge, in contrast, evaluates the evidence by reference to a mass of expert knowledge, legal, sociological, cultural, and moral, ill-represented in the statistical model.

As regards integration, the statistical models have repeatedly been shown to misrepresent cognitive process. This has been found in clinical psychology, personnel selection, and Bayesian decision theory, where statistical methods can outperform expert judges but are insensitive and misleading about cognitive process (see Anderson, 1981a, pp. 22-23, 91; 1986; Wright, 1984, Chapter 6). The same may be true for legal judgment (Ebbesen \& Konečni, 1975; see Anderson, 1982 , pp. 304, 306). For analysis of cognitive process, it is almost essential to manipulate relevant variables experimentally.

Experimental Analysis. Experimental analysis is an essential companion to observational analysis. Without experimental control of some aspects of the stimulus situation, it is exceptionally difficult and treacherous to resolve the causal ambiguities inherent in observational data. Experimental analysis of legal judgment-decision rests on three desiderata:

- causal analysis of multiple determinants,

- allowance for subjective values, and

- analysis of individual judges.

The role of these desiderata is clear. Judgment-decision in law typically involves multiple considerations. Without theory and methods that can analyze the role of each determinant in a given case, the basic process of multiple determination cannot be understood. This methodology must allow for subjective values of each determinant, moreover, for it is the meaning of the stimulus information that is the operative cognition. Since these meanings may differ for different judges, the methodology must be able to operate within the knowledge system of each individual judge.

All three desiderata are fulfilled with the functional measurement methodology of the theory of information integration. Indeed, these desiderata correspond exactly to the integration and valuation operations of the theory.

Functional measurement has several advantages over the statistical methods noted in the previous subsection, at least as these have usually been applied. Functional measurement can allow for personal values, which are essential for cognitive analysis, whereas the statistical methods depend on more or less arbitrary, nonpersonal values. Personal values make possible rigorous tests of the cognitive integration rules, which is not generally possible with the statistical methods. Moreover, functional measurement recognizes that circumstances alter cases, that the same piece of information may have different meanings in different cases. This situational, constructionist view seems essential to cognitive analysis of legal judgment. 
The central problem for experimental analysis is to relate to the functioning of a chosen legal system. Although experimental manipulation within such a setting is not generally possible, experimental analysis can still be employed to good effect, as indicated in the next subsection.

Embedding Method and Personal Design. Application of functional measurement to legal cognition may be facilitated with the embedding method and personal design. The embedding method, as the name suggests, involves embedding an integration task within a relevant social context. The purpose of the embedding is to allow experimental manipulation of some stimulus information within the chosen social context. Personal design carries this to the limit by constructing the integration task within the knowledge system of a selected individual (Anderson, in press).

Embedding within a legal setting could begin with a base case from some actual jurisdiction, selected to allow realistic manipulation of relevant variables. Variant cases would then be constructed, each differing in realistic specifics from the base case. Such variables could include severity of the offense, mitigating circumstances, motivation and personal character of the harmdoer, and so forth. By using factorial-type design, as in the present experiment, the patterning in the data can allow straightforward diagnosis of certain integration rules. Although group data were analyzed in the present experiments, the same procedures can be applied to individual data.

Personal design carries the embedding method further by using the individual for selection both of the base case and of the information variables. Task and design may both be personalized. Phenomenological and prior observational analyses could thus be incorporated within a rigorous experimental design and extended through experimental analysis. Functional measurement can allow for knowledge that does not ascend to the level of consciousness and phenomenological report. Many cognitive factors will never reach the phenomenological level. These include unconscious or unverbalizable motivations, as well as cultural and judicial assumptions so taken for granted that the judge is unaware of making them.

Some loss of realism is inevitable even with the embedding method. A personal design would ordinarily be presented in the quiet of a judge's chambers, not in the hubbub of the courtroom. Missing, therefore, would be multifarious aspects of courtroom procedure, including information cues not in the personal design, together with lapses of attention and flashes of humor and irritation that distinguish an actual court. But what is being studied is the cognitive system of the judge, which is assumed to be much the same in chambers as on the bench. The integration rules may thus be expected to have reasonable generality, even though the specific information being integrated may differ markedly across cases. The valuation processes, similarly, may be expected to be reasonably general, even though the specific information being evaluated is variable across 
cases. Although loss of courtroom realism could be serious for sociological studies of actual outcomes, many process questions can be studied outside the actual courtroom.

Two such process questions are the basal-surface representation of attitudes and the concept of functional memory (see Chapter 1 of Volume I). The basalsurface representation, which was found in an experiment using stimulus materials taken from a classic case of evidence in an actual bigamy trial (see Appendix A), implies that attitudes have two components: a labile surface component, which is easily swayed by new evidence; and an underlying basal component, which, once formed, is very resistant to change. Functional memory theory shows that judgments are not generally based on what can be recalled, as is required by the traditional conception of reproductive memory, but on cumulative integration of processed meanings of the stimulus materials. The basalsurface representation and functional memory are both important for legal psychology but neither could have been established without experimental analysis.

The case method of instruction in law has an important similarity to the embedding method. Study of past cases in lawbooks may actually have less realism than cases in a personal design, yet it is a preferred mode of instruction. The case method could, moreover, be coupled with the embedding method. Law students would thus consider, not just the single case, but a number of variant cases designed to have legal interest and to satisfy conditions for functional measurement. In this way, it may be possible to embed the study of legal cognition within legal curricula.

Acknowledgments. This work was supported by a grant from the Stiftung Volkswagenwerk, Hannover, Federal Republic of Germany, from the Deutsche Forschungsgemeinschaft, Bonn (Ho 920/2-1 and 920/2-2), and by Grants BNS79-04675, BNS80-04845, and BNS 82-12461 from the National Science Foundation. The experiments were performed during the stay of the first author at the Center for Human Information Processing, University of California, San Diego, 1978-1979. We wish to thank Ellen Himmel and Alan Anderson for their assistance. Parts of this chapter were included in Hommers and Anderson (1989). 


\section{REFERENCES}

Anderson, N. H. (1965). Averaging versus adding as a stimulus-combination rule in impression formation. Journal of Experimental Psychology, 70, 394-400.

Anderson, N. H. (1976). Social perception and cognition (Tech. Rep. CHIP 62). La Jolla, CA: Center for Human Information Processing, University of Califomia, San Diego.

Anderson, N. H. (1981a). Foundations of information integration theory. New York: Academic.

Anderson, N. H. (1981b). Integration theory applied to cognitive responses and attitudes. In R. E. Petty, T. M. Ostrom, \& T. C. Brock (Eds.), Cognitive responses in persuasion (pp. 361-397). Hillsdale, NJ: Lawrence Erlbaum Associates.

Anderson, N. H. (1982). Methods of information integration theory. New York: Academic.

Anderson, N. H. (1986). A cognitive theory of judgment and decision. In B. Brehmer, H. Jungermann, P. Lourens, \& G. Sevón (Eds.), New directions in research on decision making (pp. 63-108). Amsterdam: North-Holland.

Anderson, N. H. (Volume I, Chapter 1). Functional memory in person cognition.

Anderson, N. H. (Volume III, Chapter 5). Moral-social development.

Anderson, N. H. (in press). Personal design in social cognition. In C. Hendrick \& M. S. Clark (Eds.), Review of personality and social psychology: Vol. 11. Research methods in personality and social psychology. Beverly Hills, CA: Sage.

Anderson, N. H., \& Butzin, C. A. (1978). Integration theory applied to children's judgments of equity. Developmental Psychology, 14, 593-606.

Anderson, N. H., \& Verdi, J. (1984). Moral algebra of duty and obligation (Unpublished paper). La Jolla, CA: Center for Human Information Processing, University of Califormia, San Diego.

Bauer, G. (1984). Der Strafzumessungsvorgang als stufenweise Konkretisierung des gesetzlichen Strafrahmens (Unpublished doctoral dissertation). Mannheim: Juristische Fakultät.

Brandt, M. M., \& Strattner-Gregory, M. J. (1980). Effect of highlighting intention on intentionality and restitutive justice. Developmental Psychology, 16, 147-148.

Bruns, H. J. (1974). Strafzumessungsrecht; Gesamidarstellung (2nd ed.). Cologne: Heymanns.

Bruns, H. J. (1980). Leitfaden des Strafzumessungsrecht. Cologne: Heymanns.

Ebbesen, E. B., \& Konečni, V. J. (1975). Decision making and information integration in the courts: The setting of bail. Journal of Personality and Social Psychology, 32, 805-821.

Grueneich, R. (1982). The development of children's integration rules for making moral judgments. Child Development, 53, 887-894.

Habeman, S. J. (1978). Analysis of qualitative data (Vol. 1). New York: Academic.

Hart, H. L. A., \& Honoré, A. M. (1959). Causation in the law. Oxford: Oxford University Press.

Hommers, W. (1983a). Die Entwicklungspsychologie der Delikts- und Geschäftsfahigkeit. Göttingen: Hogrefe.

Hommers, W. (1983b). Zur quantitativen Theorie von Wiedergutmachungskognitionen unter Gewinnung ihrer Grundmerkmale aus der Jurisprudenz. In G. Lüer (Ed.), Bericht über den 33. Kongress der Deutschen Gesellschaft für Psychologie in Mainz 1982 (pp. 588-595). Göttingen: Hogrefe.

Hommers, W. (1985). Zur bipolaren moralischen Beurteilung materieller Reparationen für unterschiedlich entstandene Sachschädigungen. Zeitschrifi für experimentelle und angewandte Psychologie, 32, 425-444.

Hommers, W. (1986a). Ist "Voller Ersatz" immer "Adäquater Ersatz"? Zu einer Diskrepanz zwischen Regelungen des Gesetzbuches im EXODUS und der Adäquatheitsthese der EquityTheorie. Psychologische Beiträge, 28, 164-179.

Hommers, W. (1986b). Non-Additivität als Beleg für die moralische Natur der Integration von Schaden und Ersatzleistungen. Archiv für Psychologie, 138, 71-89. 
Hommers, W. (1986c). Zusammenwirken von Schaden und Ersatzleistung im moralischen Urteil. Zeitschrift für Entwicklungspsychologie und Pädagogische Psychologie, 18, 12-21.

Hommers, W. (1988a). Die Wirkungen von Entschuldigung und Dritt-Entschädigung auf Strafurteile über zwei Schadensarten. Zeitschrift für Sozialpsychologie, 19, 139-151.

Hommers, W. (1988b). Entschuldigung und Entschädigung für einen Diebstahl. Zeitschrift für Entwicklungspsychologie und Pädagogische Psychologie, 20, 121-133.

Hommers, W. (1988c). Implicit psychological theories in legal thought on sentencing and liability. In P. J. van Koppen, D. J. Hessing, \& G. van den Heuvel (Eds.), Lawyers on psychology and psychologists on law (pp. 67-82). Amsterdam: Swets \& Zeitlinger.

Hommers, W. (1988d). Recompense as stimulus and response: Toward an exchange of law and psychology. The German Journal of Psychology, 12, 139-151.

Hommers, W. (1989). Entschuldigung und Dritt-Entschädigung im Vergleich zur Schadenshöhe (Unpublished paper). Wurzburg: Universität Wurzburg.

Hommers, W., \& Anderson, N. H. (1985). Recompense as a factor in assigned punishment. British Journal of Developmental Psychology, 3, 75-86.

Hommers, W., \& Anderson, N. H. (1989). Algebraic schemes in legal thought and in everyday morality. In H. Wegener, F. Lösel, \& H. J. Haisch (Eds.), Criminal behavior and the justice system (pp. 136-150). Heidelberg: Springer-Verlag.

Hommers, W., \& Endres, J. (1988). Strafe und Schadensersatz als multivariater Response-Komplex. In W. Schönpflug (Ed.), Bericht über den 36. Kongress der Deutschen Gesellschaft für Psychologie in Berlin 1988 (pp. 77-78). Göttingen: Hogrefe.

Knapp, K. A. (1987). The sentencing commission's empirical research. In A. von Hirsch, K. A. Knapp, \& M. Tonry (Eds.), The sentencing commission and its guidelines (pp. 107-116). Boston, MA: Northeastern University Press.

Konečni, V. J., \& Ebbesen, E. B. (Eds.). (1982). The criminal justice system: A socialpsychological analysis. San Francisco: Freeman.

Lampel, A. K., \& Anderson, N. H. (1968). Combining visual and verbal information in an impression-formation task. Journal of Personality and Social Psychology, 9, 1-6.

Lane, J., \& Anderson, N. H. (1976). Integration of intention and outcome in moral judgment. Memory \& Cognition, 4, 1-5.

Leon, M. (1976). Coordination of intent and consequence information in children's moral judgments (Unpublished doctoral dissertation). La Jolla, CA: University of Califomia, San Diego.

Leon, M. (1980). Integration of intent and consequence information in children's moral judgments. In F. Wilkening, J. Becker, \& T. Trabasso (Eds.). Information integration by children (pp. 71-97). Hillsdale, NJ: Lawrence Erlbaum Associates.

Leon, M. (1982). Rules in children's moral judgments: Integration of intent, damage, and rationale information. Developmental Psychology, 18, 835-842.

Leon, M. (1984). Rules mothers and sons use to integrate intent and damage information in their moral judgments. Child Development, 55, 2106-2113.

Maurach, R., Gössel, K. H., \& Zipf, H. (1978). Strafrecht. Allgemeiner Teil. Teil 2. (5th ed.). Heidelberg: Müller.

Myers, M. A., \& Talarico, S. M. (1987). The social contexts of criminal sentencing. New York: Springer-Verlag.

Piaget, J. (1965). The moral judgment of the child (M. Gabain, Trans.). New York: Free Press. (Original work published 1932)

Ross, W. D. (1930). The right and the good. London: Oxford University Press.

Rousseau, J. J. (1978). Emile. (A. Bloom, Trans.). New York: Basic Books.

Shultz, T. R., Wright, K., \& Schleifer, M. (1986). Assignment of moral responsibility and punishment. Child Development, 57, 177-184. Two problems in cognitive algebra: Imputations and 
Surber, C. F. (1977). Developmental processes in social inference: Averaging of intentions and consequences in moral judgment. Developmental Psychology, 13, 654-665.

Surber, C. F. (1982). Separable effects of motives, consequences, and presentation order on children's moral judgments. Developmental Psychology, 18, 257-266.

Thomas, D. A. (1970). Principles of sentencing. The sentencing policy of the court of appeal criminal division. London: Heinemann.

Tonry, M. H. (1981). Real offense sentencing: The model sentencing and corrections act. The Journal of Criminal Law and Criminology, 72, 1550-1596.

Von Hirsch, A., Knapp, K. A., \& Tonry, M. (1987). The sentencing commission and its guidelines. Boston, MA: Northeastem University Press.

Von Linstow, B. (1974). Berechenbares Strafmass. Berlin: Schweitzer.

Walster, E., Walster, G. W., \& Berscheid, E. (1978). Equity: Theory and research. Boston: Allyn \& Bacon.

Wilkening. F., \& Anderson, N. H. (Volume III, Chapter 2). Representation and diagnosis of knowledge structures in developmental psychology.

Wilkins, L. T., Kress, J. M., Gottfredson, D. M. Calpin, J. C., \& Gelman, A. M. (1976). Sentencing guidelines: Structuring judicial discretion. Washington, DC: Criminal Justice Research Center.

Wright, G. (1984). Behavioral decision theory. Beverly Hills, CA: Sage.

Zalinski, J., \& Anderson, N. H. (Volume I, Chapter 10). Parameter estimation for averaging theory. Zipf, H. (1977). Die Strafzumessung. München: Beck. 


\section{APPENDLX}

\section{The Bigamy Trial of Thomas Hoag}

This appendix gives the stimulus materials used in the experiment that led to the basal-surface representation of attitudes (Anderson, 1959; see Figure 3 of Volume I, Chapter 1). These materials were taken from Wigmore's (1937) book on evidence, and had previously been used in a psychological experiment by Weld and Roff (1938). These stimuli include the indictment, the summarized testimony of 14 witnesses, and a denouement in the form of two pieces of court testimony that brought the trial to a close. The testimony of some witnesses was reworded to bring all to approximately equal length of 175 words.

The order of evidence is as follows: The indictment; the six prosecution witnesses used in the main design; the six defense witnesses used in the main design; two more prosecution witnesses; and finally the two pieces of court procedure. These are preceded by the first page of the subjects' booklet, which was used as part of the instructions and for adaptation to the task. The relative strengths of the 12 main pieces of evidence are tabulated at the end.

\section{EXAMPLE OF TESTIMONY (NOT RELATED TO TRIAL IN ANY WAY)}

John Doe testified, that he lived in Chicago; that he had lived in Chicago since the year 1946; that he knew the prisoner at the bar, Richard Roe, well; that witness and prisoner had worked together for many years; that in June of 1948, witness and prisoner being at work together, prisoner became faint and desired witness to bring him a glass of water which he had done; that witness thereafter assisted prisoner to his house; that prisoner remained ill for four or five weeks after which time he again resumed work; that witness was sure of the month and year because it was the same year that he and prisoner were to assist in a fireworks exhibition; that during all the years witness had known prisoner, he bore an unexceptionable character.

\section{INDICTMENT}

The prisoner was indicted for that whereas Thomas Hoag, late of Haversuaw, in the county of Rockland, laborer, otherwise called Joseph Parker, now of the city of New York, cartman, on the 8th of May, 1797, at the said city of New York, was lawfully married to Susan Faesch, and the said Susan then and there had for a wife, and the said Thomas, alias, etc., afterwards, to wit, on the 25 th day of December, 1800 , at the county of Rockland, his said wife being then in full life, feloniously did marry, and to wife did take, one Catherine Secor, etc. To this the prisoner pleaded Not Guilty. 


\section{Benjamin Coe, witness for the Prosecution}

Benjamin Coe testified, that he was one of the judges of the court of common pleas in the county of Rockland; that he well knew the prisoner at the bar; that he came to Rockland in the beginning of September, in the year 1800, and there passed by the name of Thomas Hoag; that there was a person with him who passed for his brother; but between these two persons there was no sort of resemblance; that the prisoner worked for witness about a month, during which time he ate daily at witness's table, and he, of course, saw him daily; that on the 25th day of December, 1800 , witness married the prisoner to one Catherine Secor; that witness is confident of the time, because he recollected that on that very day one of his own children was christened; that during all the time the prisoner remained in Rockland county, witness saw him continually; he was therefore as much satisfied that the prisoner was Thomas Hoag as that he himself was Benjamin Coe.

\section{Nicholas Conklin, witness for the Prosecution}

Nicholas W. Conklin testified, that he lived in Rockland county; that he knew the prisoner at the bar; that his name was Thomas Hoag; that he could not be mistaken; that Hoag had worked a considerable time for him; that during that time he had eaten at witness's table; that Hoag, being a stranger, and witness understanding that he was paying addresses to Catherine Secor, witness took a good deal of notice of him; thought him a clever fellow; lived in a house belonging to wimess. When witness saw prisoner at this place, he knew him instantly; his gait, his smile, which is a very peculiar one, his very look was that of Thomas Hoag. Hoag, he thought, was about twenty-eight or thirty years of age; he thought Hoag had a small scar on his neck. Witness endeavored, but in vain, to find some difference in appearance between the prisoner and Hoag; he was satisfied in his own mind that he is the same person.

\section{Abraham Wendell, witness for the Prosecution}

Abraham Wendell testified, that he knew one Thomas Hoag in the latter end of the year 1800; he was then in Haverstraw; that he had been very intimate with him, and knew him as well as he knew any man; that he had worked with him, had breakfasted, dined, and supped with him, and many a time had been at frolics with him. and that the prisoner at the bar was the same man; that he had no doubt whatever about it; that about a year ago, witness being in New York was told by some persons that Hoag had been concerned in an action wherein his identity had come in question; that witness told them he could know him with certainty; that they said they would send him down to him that day; that witness was aboard his sloop, saw prisoner at a distance of a hundred yards, coming down the street, and instantly knew him; prisoner came up to him and said immediately, "Mr. Wendell, I am told you will say you know me," to which witness replied, "So I do; you are Thomas Hoag;" that witness was as confident prisoner is the person, as he was of his own existence. 


\section{Lavinla Anderson, witness for the Prosecution}

Lavinia Anderson testified, that she knew the prisoner at the bar; his name was Thomas Hoag; that in September, 1800, he came to witness's house in Rockland county, and worked for her husband eight or ten days, then worked for Judge Suffrein; every Saturday night until the prisoner was married, he and a person who passed for his brother, came to witness's house and stayed till Monday morning; that witness washed for him; that there was no mark on his linen; that Hoag had a scar on his forehead which was plain to be seen on the prisoner; that Hoag's voice was very singular, shrill, thick, hurried, and something of a lisp; that Hoag had also a habit of shrugging his shoulders when he spoke, which she had also observed in the prisoner. Witness added that it was impossible that she could be mistaken--prisoner was Thomas Hoag.

\section{Michael Burke, witness for the Prosecution}

Michael Burke testified, that he lived in Catherine street in the city of New York; that he had formerly lived in Haverstraw, in Rockland county; that he saw prisoner at the bar several times at Haverstraw, before and after his marriage in December, 1800; that he was well satisfied as he could be of anything, that prisoner was the same person he knew in Haverstraw; that about two years ago he met the prisoner in the Bowery in New York, at the time of the Harlem races; prisoner spoke to witness and said, "Am I not a relation of yours?" Witness replied, "I don't know." Prisoner said, "I am; I married Katy Secor."

Upon cross-examination, witness admitted that he and prisoner had had a quarrel respecting witness calling prisoner Thomas Hoag.

\section{Catherine Conklin, witness for the Prosecution}

Catherine Conklin (formerly Catherine Secor) testified, that she became acquainted with prisoner in the beginning of September, 1800, when he came to Rockland; he then passed by the name of Thomas Hoag; that witness saw him constantly; that prisoner, shortly after their acquaintance, paid his addresses to her and finally, on the 25th of December, married her; that he lived with her till the latter end of March, 1801, when he left her; that she did not see him again until two years after; that on the morning of his leaving her, he appeared desirous of communicating something to her of importance, but was dissuaded from it by a person who was with him and who passed for his brother; that Hoag, until his departure, was a kind, attentive and affectionate husband; that she was as well convinced as she could possibly be of anything in this world, that the prisoner at the bar was the person who married her by the name of Thomas Hoag; that she then thought him and still thinks him the handsomest man she ever saw. 


\section{Elizabeth Mitchell, witness for the Defense}

Elizabeth Mitchell testified, that she knew Parker, the prisoner at the bar, well; that in 1800 and 1801 Parker lived in Capt. Pelors house adjoining witness's house; that witness was in habits of intimacy with Parker's family, and visited them constantly; that Parker being one of the city watch, she used to hear him rap with his stick at the door, to awaken his family, upon his return from the watch in the morning; that she also remembered, perfectly well, Parker's borrowing a screw for packing cotton from her on Christmas day, in 1800; she offered him some spirits to drink, but he preferred wine, which she got for him; the circumstances of her lending the screw to him she was the more positive of, from recollecting, also, that it was broken by Parker in using it; that from that time to the present day, witness had been on the same terms of intimacy with Parker's family; she therefore considered it as almost impossible that Parker could have been absent from town, any time, without her knowing it; and she never knew him to be absent more than one week, while he lived at Pelor's house.

\section{Magnus Beekman, witness for the Defense}

Magnus Beekman testified, that he had lived in New York a number of years; that he was captain of the city watch of the second district; that he was well acquainted with the prisoner at the bar, Joseph Parker; that he, Parker, had been for many years a watchman, and had done duty constantly on the watch; that he at first served as a substitute on the watch, but that later he served as a regular member of the watch; that witness recurring to his books, where he keeps a register of the watchmen and of their times of service, found that the prisoner, Joseph Parker, was regularly upon duty as a watchman during the months of October, November, and December, 1800, and January and February, 1801, and particularly that he was upon duty the 26th of December, 1800.

\section{Joseph Chadwick, witness for the Defense}

Joseph Chadwick testified, that he had been acquainted with the prisoner, Joseph Parker, a number of years; that witness resides in New York, is a rigger by trade; that the prisoner worked in the employ of the witness a considerable time as a rigger; that prisoner began to work for witness in September, 1799, and continued to work for him till the spring of 1801; that during that period he saw him constantly; that it appeared from witness's books that Parker received money from witness, for work which he had performed on the following days, viz.: on the 6th of October, and 6th and 13th December, 1800; on the 9th, 16th and 28th February, and 11th March, 1801; that Parker lived from May, 1800, till sometime in April, 1801, in a house in the city of New York belonging to Capt. Pelor; that during that period, and since, witness has been well acquainted with the prisoner. 


\section{Lewis Osborne, witness for the Defense}

Lewis Osbome testified, that he had been acquainted with Parker, the prisoner at the bar, for the last four years; that witness had been one of the city watch; that from June, 1800 , to May, 1801, Parker served upon the watch with witness; that, at first, Parker served as a substitute; that witness remembered that Parker, a few days after Christmas, in 1800 , was placed upon the roll of the regular watch, in place of one Ransom, who was taken sick; witness was certain it was in the period above mentioned, because that was the only time witness ever served upon the watch; that during the above period, witness and Parker were stationed together, while on the watch, at the same post; witness was certain that Parker, the prisoner at the bar, was the person with whom he had served upon the watch, and was confident that during that time Parker was never absent from the watch, more than a week, at any one time.

\section{James Juquar, witness for the Defense}

James Juquar testified, that he had known Joseph Parker, the prisoner at the bar, for seven years past; that he had been intimate with him at that time; that they had both worked together as riggers until Parker became a cartman; knew Parker when he lived in Capt. Pelor's house; never knew him absent from the city during this time, for a day, except when he was working on board one of the United States frigates, about a week, at Staten Island. In the year 1799, prisoner hurt himself on board the Adams frigate, and then went to his father's in Westchester county, and was absent near a month; he was very ill when he left town; witness went with him, and brought him back again, before he was quite recovered; recollects Parker and some other company passing Christmas eve at witness's house the year that Parker lived in Capt. Pelor's house, which was in 1800.

\section{Isaac Ryckman, witness for the Defense}

Isaac Ryckman testified, that he was well acquainted with Joseph Parker, the prisoner at the bar; that witness and Parker were jointly engaged in the latter part of the year 1800 , in loading a vessel for Capt. Tredwell, of New York; that they began to work on the 20th day of December, 1800, and were employed the greater part of the month of January, 1801, in the loading of the vessel; that during that time the witness and Parker worked together daily; the witness recollected well that they worked together on the 25th day of December, 1800; he remembered it because he never worked on Christmas day, before or since; and he remembered it because they borrowed a screw for the purpose of packing cotton into the hold of the vessel they were at work at, from a Mrs. Mitchell, who lived next door to Parker; that Parker was also at that time upon the watch; and that witness had served with him from that time to the present day upon the watch, and never recollected missing him any time during that period from the city. 


\section{Moses Anderson, witness for the Prosecution}

Moses Anderson testified, that he had lived in Haverstraw, Rockland county since the year 1791; that he knew the prisoner at the bar well; that he came to the house of the witness in the beginning of September, 1800; that he then passed by the name of Thomas Hoag; that he worked for the witness eight or ten days; that from that time till the 25th of December, prisoner passed almost every Sunday at witness's house; that if prisoner was the person alluded to, he had a scar on his forehead, which he told witness was occasioned by the kick of a horse; he had also a small scar on his neck (those marks the prisoner had); he had also a scar under his foot, between the heel and ball of the foot, occasioned, as he told witness, by treading on a drawing knife; that that scar was easy to be seen; that his speech was remarkable, his voice being effeminate; that he spoke quick and lisped a little (these peculiarities were observable in prisoner's speech); that witness was perfectly satisfied in his own mind that prisoner was Thomas Hoag.

\section{John Knapp, witness for the Prosecution}

John Knapp testified, that he knew the prisoner in 1800 and 1801, he was then in Rockland county, and passed by the name of Thomas Hoag; that he saw him constantly for five months, during the time the prisoner was at Rockland; that he was at the prisoner's wedding; that Hoag had a scar under his foot; the way that witness knew it, was that he and Hoag were leaping together, and witness outleaped Hoag, upon which the latter remarked that he could not leap as well now as formerly, in consequence of a wound in his foot occasioned by treading on a drawing knife; that Hoag then pulled off his shoe and showed witness the scar under his foot, occasioned by that wound; the scar was very perceptible; witness was confident prisoner at the bar was Thomas Hoag.

Here it was agreed between the attorney-general and the counsel for prisoner, that the prisoner should exhibit his foot to the jury, in order that they might see whether there was that scar which had been spoken of in such positive terms by several of the witnesses on the part of the people. Upon exhibiting his foot, not the least mark or scar could be seen on either of them.

The jury, without retiring from the bar, found a verdict of not guilty. 
The relative strengths of the testimony are given in the following tabulation. These are the means of the changes produced by each witness' testimony over stages 1-3 of the main experiment (Anderson, 1959, Figures 1-3). The design balanced particular witnesses over stages and over trials within stage. Entries are averages taken over 192 subjects.

\begin{tabular}{lr} 
Defense Witness & Strength \\
\hline & \\
Elizabeth Mitchell & 1.20 \\
Magnus Beekman & 1.20 \\
Joseph Chadwick & .56 \\
Lewis Osborne & .49 \\
James Juquar & .84 \\
Isaac Ryckmian & 1.51 \\
& \\
Prosecution Witness & Strength \\
\hline & \\
Benjamin Coe & 1.55 \\
Nicholas Conklin & .46 \\
Abraham Wendell & .70 \\
Lavinia Anderson & .84 \\
Michael Burke & .28 \\
Catherine Conklin & 1.24
\end{tabular}

\section{REFERENCES}

Anderson, N. H. (1959). Test of a model for opinion change. Journal of Abnormal and Social Psychology, 59, 371-381.

Weld , H. P., \& Roff, M. (1938). A study in the formation of opinion based upon legal evidence. American Journal of Psychology, 51, 609-628.

Wigmore, J. H. (1937). The science of judicial proof (3rd ed.). Boston: Little, Brown. 